\title{
THE CONSERVATION ROLE OF FORESTRY IN SOUTH AFRICA
}

\author{
D P ACKERMAN
}

\author{
Secretary, Department of Forestry \\ Private Bag $X 93$ \\ Pretoria \\ 0001
}

In September 1965, at the signing ceremony of a National Park Bill, United States President Johnson remarked: "We are living in the Century of Change. But if future generations are to remember us more with gratitude than with sorrow, we must achieve more than just the miracles of technology. We must also leave them a glimpse of the world as God really made it, not just as it looked when we got through with it." In the same spirit, forestry in the Republic of South Africa (RSA) shares the responsibility of conserving and restoring as far as possible the environment in which we and succeeding generations must live.

The role which forestry plays in the economic development of the RSA has long been recognised, but its other major function - the stewardship of green landscapes - may be overlooked by those who are obsessed with immediate material gain. Apart from their task of assuring the supply of timber and other forest produce for their country, foresters have a duty to preserve vegetation and other natural assets on all the land entrusted to their care which is not devoted to commercial plantations. These natural assets are not preserved purely for their own sake. Conservation is for people. Conservation costs money and the taxpayer who pays for it naturally wants to see where his money goes and enjoy the fruits of conservation, and for this reason there is a close tie between conservation and outdoor recreation.

In some parts of southern Africa nature conservation is mainly orientated to the preservation of indigenous wildlife in game parks. Many wild animals are dangerous, and visitors to the parks can view them only from motor vehicles or protected lookouts. There is clearly an imperative need for nature reserves in which the public can move without restriction beyond that which is necessary to preserve the natural wildness. In Europe and America forests constitute a significant proportion of nature reserves and they are managed by foresters to preserve and increase their scientific, aesthetic and recreational values. The establishment of forest reserves in the RSA in which the accent is on flora rather than fauna, where visitors can walk and ride, picnic and 
camp, has to date perhaps not received the attention it deserves because foresters have to some extent been pre-occupied with timber production.

Nature conservation combined with outdoor recreation and the promotion of tourism, is an aspect of land utilisation that is receiving increasing attention. In natural forests, controlled exploitation need not be excluded and open areas can even be made available to farmers for grazing in times of drought. In this way effective multiple use of the land can be achieved while still retaining public enjoyment of recreation and amenity values as an important object of management.

The recreational use of State forest land in the RSA has been sporadic and unplanned for many years. There was a tendency to regard it as a thing to be discouraged. The formulation of a definite policy for facilitating and encouraging outdoor recreation in the State forests was to a large extent the outcome of a visit to the RSA in 1962 by Prof C F Brockman of the School of Forestry and Natural Resources of the University of Washington, who expressed the following views in reporting on his tour:

". . . it is quite evident that in addition to wood production your forests, too, can become of increasing importance in outdoor recreation for the following reasons:

(i) Their scenic beauty and predominantly mountain settings.

(ii) Accessibility to motorists along a number of main roads and the possibility of opening forest roads to the public.

(iii) The possibility of developing a wide variety of interests and activities for visitors in certain areas."

The conservation role of forestry can be best appreciated if we go back to the original meaning of the word forest. It is derived from the Latin "foris" meaning "outside" and forestis in the Latin of the middle ages came to mean an unenclosed area lying outside the boundaries of villages or parks. Originally, therefore, forest referred to all uncultivated or untended land, which in Europe would in the main have had trees growing on it, but would also have included scrub, wasteland and what we call veld and savannah. Nowadays we think of a forest as a plant community in which a fairly dense growth of trees is dominant. Terms such as "high forest", "scrub forest" and "savannah" are used, but those who think of forestry primarily as a commercial undertaking are inclined to envisage a forest essentially as a regimented "plantation" with trees "lined up and lopped and drilled" to create a mechanistic, artifically-maintained sawlog factory, rather than an independently viable association of plants and animals - a biocoenose - adapted to the environment - a forest ecosystem.

The direct value of forests as a source of forest produce and the indirect benefits flowing from their amenity values, are both important, 
but the emphasis on one or other type of benefit has varied because of differences in the socio-economic conditions of the country in the historical period concerned. In ancient times the forest was a refuge for people from their enemies and a shelter from inclement weather. It may also have harboured rogues and criminals. At a later stage many forests were reserved for hunting and pleasure. The direct value of forests as sources of timber and other products did not exceed the indirect values until the industrial revolution sharply increased the demand for timber from the end of the 18th century onwards. The continuous growth of industry since then and the pressure of expanding population are still causing increased demands for timber and other forest products, but in those areas such as western Europe and the eastern United States where industrial civilisation has attained its greatest development, the accessory benefits of forest land have come to be accepted as of paramount importance.

Governments have realised that there is much more to forestry than the establishment and management of plantations for immediate profits, the exploitation of natural forests and the operation of sawmills, pulpmills and other wood-processing plants. The practice of forestry also includes the preservation and management of water catchments, the conservation of nature reserves in natural forests and other categories of land and the development of outdoor recreation facilities. Foresters stabilise drifting sands and give expert advice on the choice of trees for woodlots, shade, shelter and ornament on farms and in parks and gardens and along streets in urban areas. The maintenance of adequate green areas is also an essential aspect of the forester's task.

You may ask what the Department of Forestry has done in the RSA to conserve the natural vegetation. The Department of Forestry is probably best known to the public for the plantations of exotics, mainly pines, which it has established for the production of timber. It is perhaps not so widely realised that the Department was the first body in the RSA to concern itself with conservation of the country's indigenous flora.

The first step taken to protect the indigenous forests of the southern Cape from the destructive exploitation then taking place, was the closure of these forests by the Colonial Administration of the Cape in 1846 at the instance of its Forest Service. These forests were subsequently re-opened to controlled exploitation but with the passage of time control was intensified by successive legal enactments culminating in 1939 with the de-registration of the remaining woodcutters who were granted state pensions in lieu of their right to fell and market timber from these forests. Since that time all indigenous forests belonging to the state have been managed strictly on a conservation basis. Active research is being undertaken with the object of rehabilitating and consolidating these forests. Legislation aimed at the acquisition of suitable privately-owned indigenous forests has also been enacted. If forest officers had not fought with dedicated determination to preserve the indigenous forests and if 
alternative timber resources in the form of plantations had not been established, it can be accepted that very little of these forests would remain today.

Provision is made in the Forest Act for the protection of any tree species or forest by proclamation, and a list of protected trees, which may not be felled without the authority of the Minister, has been drawn up and published. Several private forests in the southern Cape have been likewise protected.

Included in the area controlled by the Department are 30 nature reserves comprising some 7500 ha, which are managed for the conservation of specific rare plant species or ecosystems. The Department's main conservation operations, however, are conducted in the mountain catchment reserves which exceed a million hectares in extent. They are managed primarily for the optimum yield of clear water, but this objective is fully compatible with the conservation of the flora and the maintenance of a favourable habitat for wild life. The area of mountain catchments is being steadily increased by the acquisition of suitable land. An expanding staff of conservation officers which includes plant and animal ecologists, is employed on research aimed at the establishment of the most effective methods of management for maximum yield of pure, silt-free water in conjunction with protection of the fauna and flora. Rare and endangered plant and animal species receive special attention. Research is also being undertaken into the re-introduction of animals, such as eland, and other antelope into State forests where they formerly lived but have long since disappeared. Special conservation research projects on State forest land are being conducted on behalf of the Department by universities and provincial nature conservation departments.

In recent years there has been a growing awareness, in the RSA as in other western countries, of the need to conserve primitive environments where people of this and future generations can study ecosystems virtually unaltered by man; where they can enjoy landscapes unscarred by roads, railways or power lines; where they can find peace and solitude; and where they can pit their own unaided resources against the forces of nature.

Although all demarcated forests enjoy a degree of entrenchment under the Forest Act of 1968, there was a need for the special preservation of selected areas which had retained their original wild character before they too would be changed by technological progress. The Forest Act was accordingly amended in 1971 to empower the Minister, on the recommendation of the National Monuments Council, to set aside State Forests or portions of state forests as wilderness Areas for the preservation of forests and natural scenery. Areas so proclaimed cannot be alienated nor can any rights be granted over them except with the approval of the Senate and the House of Assembly. Five wilderness areas, totalling an area of nearly 185000 ha, have already been 
proclaimed and a number of others, making up an even larger area, are under consideration.

To make conservation areas accessible to people, the Department is engaged in the development of a system of hiking trails on the lines of the Appalachian Trail in the eastern United States and similar trails in other countries. The South African trail with its supplementary routes is intended ultimately to stretch continuously from the Cedarberg in the western Cape along the mountains following the southern and eastern coastlines to terminate in the Soutpansberg in the northern Transvaal. The trail is not confined to State forest land and it is controlled by the National Hiking Way Board on which State Departments, Provincial Administrations, the National Parks Board and mountain and other outdoor clubs are represented.

The system consists basically of hiking trails and walks. Hiking trails are longer than walks and include overnight facilities such as huts, shelters and sites for tents. Hiking trails are more strenuous than walks and cater for those who wish to carry a backpack or rucksack through relatively undeveloped lands with overnight shelters. Walks provide leisurely outings through selected environments lasting a few hours and do not include overnight facilities. The following sections have been completed and are open for public use:

the Fanie Botha Hiking Trail from near Sabie to beyond Graskop;

the Soutpansberg Hiking Trail along the Soutpansberg eastwards from above Louis Trichardt; and

the Elephant Walk in the Diepwalle State Forest near Knysna.

Three other sections are due for completion by February 1977. The National Parks Board's spectacular Otter Hiking Trail along the Tsitsikama coast from Stormsrivier to Grootrivier will also form a link in the system.

Since the Fanie Botha Hiking Trail was opened in 1973, usage has increased and it is expected that there will be regular growth in the number of hikers using the already completed sections. It can be confidently expected that the time will come when a significant proportion of the active population in the more thickly populated areas will be attracted to these gateways to the untrammelled outdoors. The trails and walks can bring large numbers of the public, and particularly the impressionable younger segment, into closer contact with nature and all her wonders. This cannot fail to foster the cause of conservation in the RSA and to bring into many lives a deep appreciation of the need to preserve the green heritage which is their birthright.

The Department makes a major contribution to the conservation of a number of the country's veld types on its mountain catchment reserves. One of its most important functions is the permanent protection of the Cape Fynbos which comprises one of the richest and most diverse floras in the world. Rapid agricultural and industrial development has resulted in the sacrifice of many hectares of Fynbos. Were it not for the protection 
by the Department of its mountain catchments, the flora in these areas would be sadly depleted. The mountain catchments provide a last refuge for many of South Africa's most beautiful flowering plants and several rare and endangered species. Through dedicated research and farsighted conservation planning, excellent progress has been made with the rehabilitation of many endangered species.

Conservation of fauna also has a high priority on all State forests, and good progress has been made in this direction. It is not generally realised that plantations of exotic species also provide excellent cover for game, which has increased spectacularly in numbers on many State forests. The periodic burning of firebreaks provides grazing for the game which finds sanctuary in the plantations.

Large sums of money are spent on the eradication of undesirable alien vegetation growing on State forest land. The problem presented by the intrusion of aggressive exotic species is daunting in its magnitude. It can be tackled successfully only by the application of co-ordinated national effort backed by adequate finance. The matter is receiving attention at the highest levels and continuous research is directed at finding cheaper and more effective methods of control.

The valuable work being done by forestry bodies in the reclamation of driftsands along the South African coastline is well known. In this we are following the example of Denis the First of Portugal, who pioneered the reclamation of coastal dunes 500 years ago by planting them with the Maritime Pine. The timber from these plantations was used in shipbuilding. Reclaimed driftsand has made valuable residential and industrial development possible, especially in the expansion of the cities of Cape Town and Port Elizabeth. Casuarina species have also been used in the reclamation of coastal driftsands in the summer rainfall area.

Although progress made by the Department in all aspects of nature conservation in the RSA is impressive, much still remains to be done. The scale and scope of the work is being expanded as rapidly as the recruitment of trained conservation staff and availability of funds permit. Although the RSA is fortunate in having large areas of open veld and mountain, the threat posed by the encroachment of the growing population and expanding industries is very real. Pollution of the atmosphere and water supplies, and indeed of our whole environment, is a danger we dare not ignore simply because it is not as immediately threatening to us as it is in some of the more intensively industrialised countries.

The fact must be faced - pollution is no longer a problem peculiar to the densely-populated, highly-industrialised countries. It has become a universal problem and we in the RSA must join in the fight against it now. We all have a responsibility to play a full part in exercising the stewardship of the green landscape. Let us take timely and effective action to preserve the land entrusted to our care by meticulously planning the conservation of water sources, soil and vegetation, and providing 
facilities for outdoor recreation to attract tourists as well as our own people out into the open to enjoy pure air, sparkling waters, undisturbed vegetation and protected wildlife. May I conclude by asserting that the planting of trees has a rightful place in these plans. Trees are essential to satisfy the national demand for forest products but they can also beautify and conserve the South African environment. 